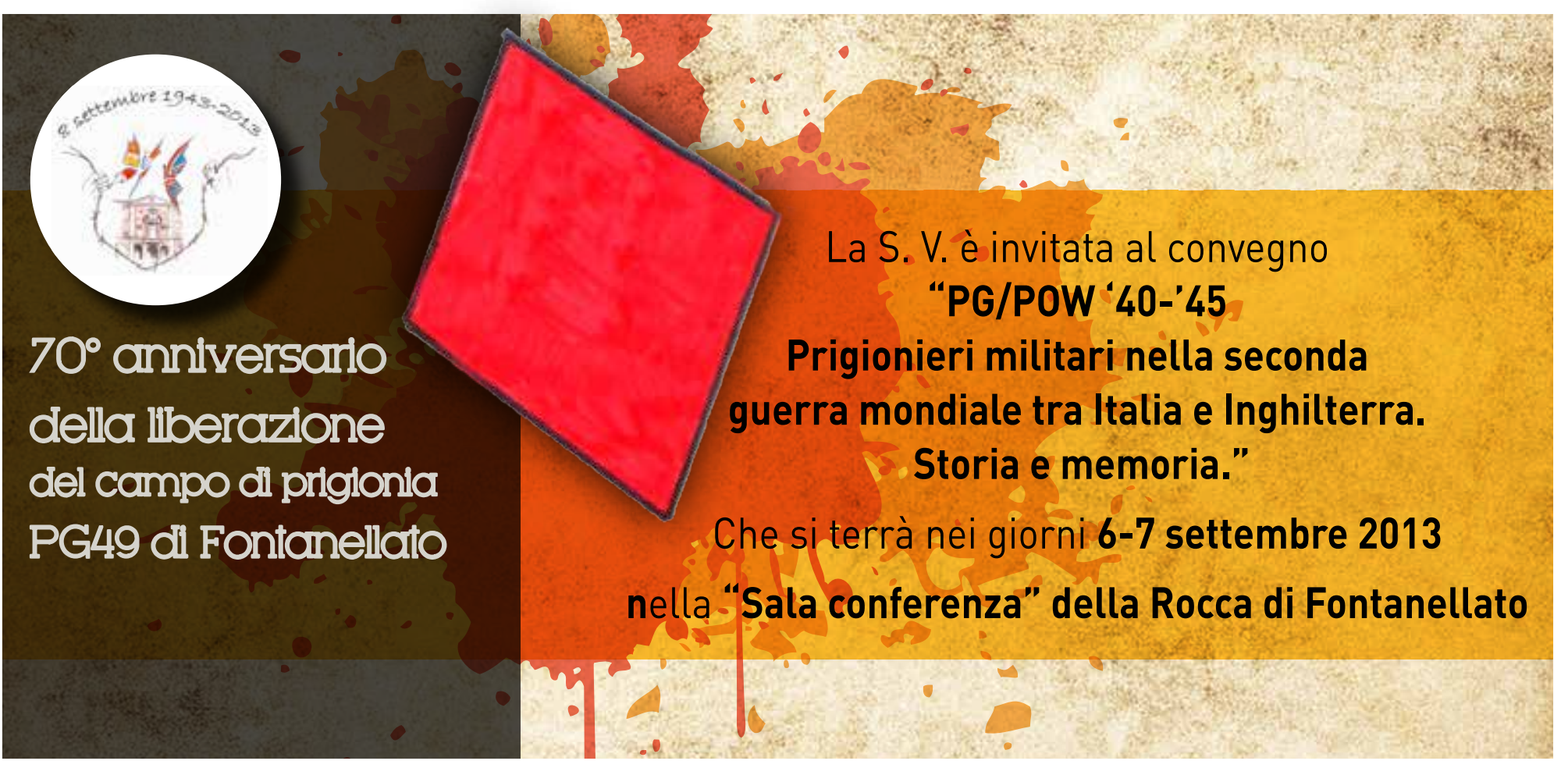




\section{Prigionieri militari nella seconda guerra mondiale tra Italia e Inghilterra. Storia e memoria.}

Sala conferenze Rocca Sanvitale Fontanellato

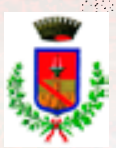

Comune di

Fontanellato

$$
\text { 1+t) }
$$

PROVINCIA DI PARMA

RegioneEmilia-Romagna

$18+1,010$

stonis:

ond

c 0 tom

parma.

ISTITUTO PER LA STORIA E LE MEMORIE DEL 900 PARRI E-R
PROCRAMMA

Venerdi 6 settembre

ore $15.30-18.00$

+ Saluti delle autorità

Presiede: Lorenzo Bertucelli

(Fossoli Fondazione ex-campo)

+ Una guerra di soldati?

L'Africa Settentrionale nel quadro

della Seconda guerra mondiale

Marco Di Giovanni (Università di Torino) discussione

+ I "fortunati": i prigionieri italiani in Gran Bretagna, 1941-1946

Isabella Insolvibile (Università di Napoli)

discussione
Sabato 7 settembre

ore $10.00-12.30$

Presiede: Luca Alessandrini

(Istituto per la storia e le memorie del 900 Parri E-R)

+ Prigionieri in fuga dopo l' 8 settembre ' 43 tra salvataggi e brutalità

Marco Minardi (Istituto storico della

Resistenza e dell'età contemporanea di Parmal discussione

+ The British serviceman's experiences in Italian prisoners of war camps

Clare Makepeace

(Birkbeck College, Università di Londra) discussione 